medRxiv preprint doi: https://doi.org/10.1101/2021.08.05.21261658; this version posted August 7, 2021. The copyright holder for this preprint (which was not certified by peer review) is the author/funder, who has granted medRxiv a license to display the preprint in It is made available under a CC-BY 4.0 International license.

\title{
Separating the direct effects of risk factors for atherosclerotic cardiovascular disease from those mediated by type 2 diabetes
}

\author{
Venexia M Walker ${ }^{1,2,3}$, Marijana Vujkovic ${ }^{3}$, Alice R Carter $^{1,2}$, \\ Neil M Davies ${ }^{1,2,4}$, Miriam S Udler ${ }^{5}$, Michael G Levin ${ }^{6,7}$, George Davey Smith ${ }^{1,2}$, \\ Benjamin F Voight ${ }^{8,9,10}$, Tom R Gaunt ${ }^{1,2}$, Scott M Damrauer ${ }^{3,8}$
}

(1) MRC University of Bristol Integrative Epidemiology Unit, Bristol, UK

(2) Bristol Medical School: Population Health Sciences, University of Bristol, Bristol, UK

(3) Department of Surgery, University of Pennsylvania Perelman School of Medicine, Philadelphia, USA

(4) K.G. Jebsen Center for Genetic Epidemiology, Department of Public Health and Nursing, NTNU, Norwegian University of Science and Technology, Norway

(5) Center for Genomic Medicine, Massachusetts General Hospital, Boston, USA

(6) Division of Cardiovascular Medicine, University of Pennsylvania Perelman School of Medicine, Philadelphia, USA

(7) Department of Surgery, Corporal Michael Crescenz VA Medical Center, Philadelphia, USA

(8) Department of Systems Pharmacology and Translational Therapeutics, University of Pennsylvania Perelman School of Medicine, Philadelphia, USA

(9) Department of Genetics, University of Pennsylvania Perelman School of Medicine, Philadelphia, USA

(10) Institute of Translational Medicine and Therapeutics, University of Pennsylvania Perelman School of Medicine, Philadelphia, USA

Correspondence to: Venexia Walker; Bristol Medical School, University of Bristol, Oakfield House, Oakfield Grove, Bristol, BS8 2BN; venexia.walker@bristol.ac.uk 
medRxiv preprint doi: https://doi.org/10.1101/2021.08.05.21261658; this version posted August 7, 2021. The copyright holder for this preprint (which was not certified by peer review) is the author/funder, who has granted medRxiv a license to display the preprint in It is made available under a CC-BY 4.0 International license.

\section{ABSTRACT}

Background: Type 2 diabetes and atherosclerotic cardiovascular disease share several risk factors. However, it is unclear whether the effect of these risk factors on liability to atherosclerotic cardiovascular disease is independent of their effect on liability to type 2 diabetes.

Methods: We performed univariate Mendelian randomization to quantify the effects of continuous risk factors from the IEU OpenGWAS database on liability to three outcomes: type 2 diabetes, coronary artery disease, and peripheral artery disease, as well as the effects of liability to type 2 diabetes on the risk factors. We also performed two-step Mendelian randomization for mediation to estimate the mediating pathways between the risk factors, liability to type 2 diabetes, and liability to the atherosclerotic cardiovascular disease outcomes where possible.

Results: We found evidence for 53 risk factors as causes of liability to coronary artery disease, including eight which were causes of liability to type 2 diabetes only and four which were consequences only. Except for fasting insulin and hip circumference, the direct and total effects from the two-step Mendelian randomization were similar. This suggests that the combination of these risk factors with liability to type 2 diabetes was unlikely to alter liability to coronary artery disease beyond their individual effects. We also found 13 risk factors that were causes of liability peripheral artery disease, including six which were causes of liability to type 2 diabetes only and four which were consequences only. Again, the direct and total effects were similar for these ten risk factors apart from fasting insulin.

Conclusions: Most risk factors were likely to affect liability to atherosclerotic cardiovascular disease independently of their relationship with liability to type 2 diabetes. Control of modifiable risk factors therefore remains important for reducing atherosclerotic cardiovascular disease risk regardless of patient liability to type 2 diabetes. 
medRxiv preprint doi: https://doi.org/10.1101/2021.08.05.21261658; this version posted August 7, 2021. The copyright holder for this preprint (which was not certified by peer review) is the author/funder, who has granted medRxiv a license to display the preprint in It is made available under a CC-BY 4.0 International license.

\section{RESEARCH IN CONTEXT}

What is already known about this subject?

- Type 2 diabetes, coronary artery disease and peripheral artery disease, share several risk factors

- Type 2 diabetes is also one of the strongest independent risk factors for both coronary and peripheral artery disease

What is the key question?

- Which risk factors for atherosclerotic cardiovascular disease are mediated by liability to type 2 diabetes and which are independent?

What are the new findings?

- Among 108 risk factors in this study, there was evidence to support: 10 risk factors as causes, 23 risk factors as consequences, and 34 risk factors as both causes and consequences of liability to type 2 diabetes

- In addition, we found evidence for 53 risk factors as causes of liability to coronary artery disease and 42 risk factors as causes of liability to peripheral artery disease

- Using two-step Mendelian randomization for mediation, we found most risk factors for atherosclerotic cardiovascular disease were likely to act independently of liability to type 2 diabetes

How might this impact on clinical practice in the foreseeable future?

- Our findings support continued control of modifiable risk factors as this is likely to reduce atherosclerotic cardiovascular disease, regardless of patient liability to type 2 diabetes

\section{WORD COUNT}

\section{8 words}


medRxiv preprint doi: https://doi.org/10.1101/2021.08.05.21261658; this version posted August 7, 2021. The copyright holder for this preprint (which was not certified by peer review) is the author/funder, who has granted medRxiv a license to display the preprint in It is made available under a CC-BY 4.0 International license.

\section{INTRODUCTION}

Type 2 diabetes and atherosclerotic cardiovascular diseases, coronary artery disease and peripheral artery disease, share several risk factors, such as obesity and hypertension (1-3). In addition, type 2 diabetes is one of the strongest independent risk factors for both coronary and peripheral artery disease $(4,5)$. Primary prevention strategies for both diabetes and atherosclerotic cardiovascular disease focus on lifestyle modification to improve the shared set of cardiometabolic risk factors including obesity, hypertension, and dyslipidaemia. $(6,7)$ However, despite the shared links between cardiometabolic risk factors, diabetes, and atherosclerotic cardiovascular disease, the effects of risk factors on liability to atherosclerotic cardiovascular disease, both through and independent of liability to type 2 diabetes, has not been systematically assessed.

Mendelian randomization uses genetic variants associated with an exposure - referred to as an 'instrument' - as a proxy for that exposure. (8) Mendelian randomization can be used to estimate the causal effect of an exposure on an outcome free from bias due to non-genetic confounding and reverse causality if its assumptions hold (Supplementary Text 1). (9) Two-step Mendelian randomization for mediation analysis is an extension to this method, which incorporates the causal effect of a mediator, to estimate the direct (independent of the mediator) and indirect (via the mediator) effects of an exposure on an outcome. $(10,11)$ Furthermore, this approach can be applied using summary statistics from multiple genome-wide association studies (GWASs) with non-overlapping samples. (12) This removes the need for individual level data from a single study containing information on all the risk factors.

Mendelian randomization has previously been used to individually estimate the effect of several risk factors on liability to our three disease outcomes of interest: type 2 diabetes, coronary artery disease, and peripheral artery disease. $(4,13-17)$ Mendelian randomization for mediation has also been conducted to investigate the effect of a selected set of obesity-related markers (genetically predicted BMI and waist-hip ratio) on liability to coronary artery disease, peripheral artery disease and stroke, mediated by genetically predicted systolic blood pressure, liability to type 2 diabetes, lipid risk factors and smoking. (18) However, systematic assessment of a wide range of risk factors using Mendelian randomization to separate their effects on liability to atherosclerotic cardiovascular disease from liability to type 2 diabetes has not yet been conducted. 
medRxiv preprint doi: https://doi.org/10.1101/2021.08.05.21261658; this version posted August 7, 2021. The copyright holder for this preprint (which was not certified by peer review) is the author/funder, who has granted medRxiv a license to display the preprint in It is made available under a CC-BY 4.0 International license.

In this study, we implemented a standardized univariate Mendelian randomization framework and followup analyses with two-step Mendelian randomization for mediation to interrogate the association of a broad range of continuous risk factors with liability to our three disease outcomes: type 2 diabetes, coronary artery disease, and peripheral artery disease. The aim of this study was to separate the direct effects of the risk factors on atherosclerotic cardiovascular disease from those mediated by liability to type 2 diabetes.

\section{METHODS}

\section{Study design}

Our study consisted of two stages, which are summarised in Figure 1. First, we used univariate Mendelian randomization to estimate the effects of 108 continuous risk factors (see: Risk factor selection) on liability to three disease outcomes: type 2 diabetes, coronary artery disease, and peripheral artery disease. In addition, we used univariate Mendelian randomization to estimate the effect of liability to type 2 diabetes on the 108 continuous risk factors. This allowed us to remove risk factors that had a bidirectional association with liability to type 2 diabetes, which may indicate interaction of the phenotypes and violate the assumptions required for the subsequent mediation stage. Based on the evidence from stage 1, we implemented stage 2: two-step Mendelian randomization for mediation, which assumes no interaction between the exposure and the mediator. Using this approach, we estimated the direct (i.e., the effect independent of liability to type 2 diabetes) and indirect effects (i.e., the effect mediated via liability to type 2 diabetes) of the risk factors on the atherosclerotic cardiovascular diseases of interest.

\section{Risk factor selection}

Risk factors were selected from the IEU OpenGWAS database by implementing a selection procedure to retain the largest, minimally adjusted GWAS for each continuous biological trait that had been studied in both men and women of European or mixed ancestry (Supplementary Figure 1). (19) Sample overlap was permitted between risk factors and so the majority of GWAS included participants from UK Biobank. (20)

\section{Outcome phenotypes}

We obtained the GWAS for liability to type 2 diabetes in European ancestry from the DIAMANTE consortium. (21) The GWAS for liability to coronary artery disease and liability to peripheral artery disease 
medRxiv preprint doi: https://doi.org/10.1101/2021.08.05.21261658; this version posted August 7, 2021. The copyright holder for this preprint (which was not certified by peer review) is the author/funder, who has granted medRxiv a license to display the preprint in It is made available under a CC-BY 4.0 International license.

were obtained from the CARDIoGRAM consortium and Million Veteran Program respectively. (22-24) As noted above, sample overlap was permitted between risk factors, however GWAS were obtained from distinct samples for liability to type 2 diabetes, coronary artery disease, and peripheral artery disease.

\section{Univariate Mendelian randomization}

Instruments for each risk factor were defined using the genome-wide significant $(p<5 e-8)$ genetic variants from the corresponding GWAS to satisfy the first instrumental variable assumption of relevance. For the univariate Mendelian randomization analyses, instruments were clumped using a $10 \mathrm{Mb}$ window and $\mathrm{R}$ squared linkage disequilibrium (LD) threshold of 0.001 against the 1000 genomes reference panel for the European super-population, which was filtered to include only bi-allelic variants with minor allele frequencies greater than 0.01 . Instruments consisting of less than 10 variants were removed, before harmonization with the outcome data to represent an increase in the exposure. Mendelian randomization was then performed using the inverse variance weighted method.

We repeated the above univariate Mendelian randomization analyses using the simple mode, weighted median, weighted mode, and MR-Egger methods as a sensitivity analysis to examine estimate consistency. We also derived heterogeneity statistics to examine the consistency of estimates across the variants included in each analysis and performed a leave-one-out analysis to determine whether certain variants were driving the observed effects. We included an MR-Egger intercept test to assess if directional pleiotropy was likely to have affected our results. (25) Finally, to assess the no measurement error assumption for MR-Egger, we calculated the $I_{G X}^{2}$ statistic as a measure of potential attenuation bias. (26) All univariate analyses and associated sensitivity analyses were implemented using the TwoSampleMR package for R. (27)

\section{Two-step Mendelian randomization for mediation}

For risk factors with both (i) evidence of a unidirectional association with liability to type 2 diabetes (in either direction) and (ii) evidence of an effect on liability to at least one atherosclerotic cardiovascular outcome of interest, multivariable Mendelian randomization was applied using the risk factor and liability to type 2 diabetes as exposures. As noted previously, evidence of a unidirectional association with liability to type 2 diabetes is necessary, as two-step Mendelian randomization for mediation assumes no interaction between the exposure and the mediator, which we cannot rule out when a bidirectional 
medRxiv preprint doi: https://doi.org/10.1101/2021.08.05.21261658; this version posted August 7, 2021. The copyright holder for this preprint (which was not certified by peer review) is the author/funder, who has granted medRxiv a license to display the preprint in

It is made available under a CC-BY 4.0 International license.

association between a risk factor and liability to type 2 diabetes is observed. An arbitrary false discovery rate (FDR) of 5\%, calculated according to the Benjamini and Hochberg method, was used as an indicator of supportive evidence of an association between risk factors and liability to type 2 diabetes. (28)

Based on the direction of the effect between the risk factor and liability to type 2 diabetes, multivariable Mendelian randomization allowed us to estimate either (i) the effect of the risk factor, independent of liability to type 2 diabetes, on the liability to atherosclerotic cardiovascular outcome of interest (Figure 1, panel B) or (ii) the effect of liability to type 2 diabetes, independent of the risk factor, on the liability to atherosclerotic cardiovascular outcome of interest (Figure 1, panel C). These effects are often referred to as 'direct' effects. Where appropriate, we also derived either (i) the effect of the risk factor, through liability to type 2 diabetes, or (ii) the effect of liability to type 2 diabetes, through the risk factor, on liability to the atherosclerotic cardiovascular outcome of interest. These effects are often referred to as 'indirect' or 'mediated' effects. For these analyses, we multiplied the estimate for the effect of the exposure of interest on the mediator obtained from the univariate Mendelian randomization by the direct effect of mediator on the outcome obtained from the multivariable Mendelian randomization (where the exposure of interest and mediator were both used as exposures). Confidence intervals were derived using the sum of squares method.

Instruments for this analysis were clumped against either the risk factor or liability to type 2 diabetes (whichever GWAS had the smallest instrument) using a 10Mb window and R squared LD threshold of 0.001 against the 1000 genomes reference panel for the European super-population, which was filtered to include only bi-allelic variants with minor allele frequencies greater than 0.01 . Harmonisation was performed with variants aligned to represent an increase in the exposure prior to analysis. We calculated conditional F statistics to test instrument strength for each exposure in our analysis. We also calculated a modified form of Cochran's $Q$ statistic that has been developed to measure heterogeneity in causal effect estimates from multivariable Mendelian randomization. Multivariable Mendelian randomization estimates and these statistics were obtained using the MVMR package for R. (29) The non-collapsibility of odds ratios can pose a problem when using summary statistics from logistic regression for binary mediators and outcomes in multivariable Mendelian randomization. To assess whether this is likely to have impacted our results, we repeated our analyses using a GWAS of liability to type 2 diabetes based on a linear (instead of a logistic) model (Supplementary Text 2). 
medRxiv preprint doi: https://doi.org/10.1101/2021.08.05.21261658; this version posted August 7, 2021. The copyright holder for this preprint (which was not certified by peer review) is the author/funder, who has granted medRxiv a license to display the preprint in It is made available under a CC-BY 4.0 International license.

\section{Code availability}

All analyses were conducted in $\mathrm{R}$ version 4.0.2. The associated code is available from: https://github.com/venexia/T2DMediationMR.

\section{RESULTS}

The results of this analysis are presented in four parts. First, the selection of risk factors from the IEU OpenGWAS database. (19) Second, the results of the univariate Mendelian randomization analyses to interrogate the effect of each risk factor on liability to type 2 diabetes and the effect of liability to type 2 diabetes on each risk factor. Third, the results related to liability to coronary artery disease from both the univariate Mendelian randomization and two-step Mendelian randomization for mediation. Fourth, and finally, results related to liability to peripheral artery disease from the univariate Mendelian randomization and two-step Mendelian randomization for mediation.

\section{Risk factor selection}

We identified 108 risk factors from the IEU OpenGWAS database for inclusion in our analysis. (19) Details of both the risk factor and outcome GWASs are provided in Supplementary Table 1. The majority of the risk factor GWASs were conducted in UK Biobank by the Neale lab. (30) Twelve of the selected GWASs were from other sources: adiponectin (31); alcoholic drinks per week (32); body fat (33); body mass index (34); cigarettes per day (32); fasting glucose (35); fasting insulin (35); heart rate (36); neuroticism (37); total cholesterol (38); urinary sodium-potassium ratio (39); and waist-to-hip ratio (40).

\section{Causes and consequences of liability to type 2 diabetes}

Estimates from bidirectional univariate Mendelian randomization of each risk factor and liability to type 2 diabetes found evidence for: 10 risk factors as causes, 23 risk factors as consequences, 34 risk factors as both causes and consequences, and 41 risk factors as neither causes nor consequences of liability to type 2 diabetes at an FDR threshold of 5\% (Supplementary Figures 2 and 3; Supplementary Table 2). Sensitivity analyses using alternative Mendelian randomization methods were consistent with the inverse variance weighted estimates (Supplementary Figures 4 and 5; Supplementary Table 2). The MR-Egger intercept test found intercepts between -0.15 (body fat on liability to type 2 diabetes) and 0.07 (fasting glucose on liability to type 2 diabetes) (Supplementary Table 3). Finally, the $I_{G X}^{2}$ statistic was over 0.93 for all MR 
medRxiv preprint doi: https://doi.org/10.1101/2021.08.05.21261658; this version posted August 7, 2021. The copyright holder for this preprint (which was not certified by peer review) is the author/funder, who has granted medRxiv a license to display the preprint in

It is made available under a CC-BY 4.0 International license.

Egger results (Supplementary Table 4). When taken as an estimate of the attenuation bias in these analyses, this corresponds to less than $7 \%$ relative bias towards the null. Based on the findings from these bidirectional univariate Mendelian randomization analyses, 33 of the 108 risk factors were eligible for the two-step Mendelian randomization for mediation analyses for liability to atherosclerotic cardiovascular disease that followed.

\section{Causes of liability to coronary artery disease}

Using univariate Mendelian randomization, we found evidence for 53 of the 108 risk factors as causes of liability to coronary artery disease at the FDR threshold of 5\%. Twelve of these risk factors also had a unidirectional association with liability to type 2 diabetes and so were eligible for two-step Mendelian randomization for mediation (Supplementary Figures 6 and 7; Supplementary Tables 2 and 5). Using the risk factor as the exposure and liability to type 2 diabetes as the mediator for the eight risk factors identified as causes of both liabilities to type 2 diabetes and coronary artery disease, we found similar direct and total effects for most risk factors: Apolipoprotein B, aspartate aminotransferase, diastolic blood pressure, standing height, total cholesterol, and trunk fat percentage (Figure 2; Supplementary Table 6). The exceptions were fasting insulin and hip circumference, where the effects indicated partial mediation by liability to type 2 diabetes. For the remaining four risk factors (mean corpuscular haemoglobin, mean sphered cell volume, testosterone, urate), we used liability to type 2 diabetes as the exposure and the risk factor as the mediator as they had been identified as consequences, rather than causes, of liability to type 2 diabetes. In this analysis, we found similar direct and total effects in all cases, suggesting that the risk factor and liability to type 2 diabetes were likely to have independent effects on liability to coronary artery disease (Figure 3; Supplementary Table 6). The conditional F statistics for the multivariable Mendelian randomization component of these analyses ranged from 9 to 87 (Supplementary Table 6), indicating good instrument strength. Meanwhile, the modified Cochran's Q statistic exceeded the critical value for the $\mathrm{X}^{2}$ distribution at the $5 \%$ level for all analyses. This indicated that the chosen SNPs predicted both the risk factor and liability to type 2 diabetes in the data. Taken as a whole, the analyses concerning liability to coronary artery disease suggest that the effects of the risk factors are likely independent of the effects of liability to type 2 diabetes for the most part.

\section{Causes of liability to peripheral artery disease}

We found evidence for 42 risk factors as causes of liability to peripheral artery disease at the FDR threshold of $5 \%$ using univariate Mendelian randomization. We performed two-step Mendelian randomization for 
medRxiv preprint doi: https://doi.org/10.1101/2021.08.05.21261658; this version posted August 7, 2021. The copyright holder for this preprint (which was not certified by peer review) is the author/funder, who has granted medRxiv a license to display the preprint in perpetuity

It is made available under a CC-BY 4.0 International license.

mediation on 10 of these 42 risk factors with evidence to support a unidirectional association with liability to type 2 diabetes (Supplementary Figures 8 and 9; Supplementary Tables $\mathbf{2}$ and 5). Using the risk factor as the exposure and liability to type 2 diabetes as the mediator for the six risk factors (Apolipoprotein B, diastolic blood pressure, fasting insulin, hip circumference, total cholesterol, and trunk fat percentage) identified as causes of both liability to type 2 diabetes and liability to coronary artery disease, we found similar direct and total effects in most cases (Figure 4; Supplementary Table 6). Fasting insulin was again identified as an exception with effects that indicated partial mediation by liability to type 2 diabetes. For the other four risk factors (alcohol intake frequency, cigarettes per day, sodium in urine, and urate), we used liability to type 2 diabetes as the exposure and the risk factor as the mediator and found similar direct and total effects in all cases (Figure 5; Supplementary Table 6). The conditional F statistics for the multivariable Mendelian randomization component of these analyses again indicated good instrument strength, ranging from 9 to 86 (Supplementary Table 6). We also found the modified Cochran's Q statistic exceeded the critical value for the $\mathrm{X}^{2}$ distribution at the $5 \%$ level for all liability to peripheral artery disease analyses. Similar to the results concerning liability to coronary artery disease, these analyses suggest that the effects for the majority of risk factors on liability to peripheral artery disease are likely to be independent of the effects of liability to type 2 diabetes.

\section{DISCUSSION}

This study found evidence for the causal effects of multiple risk factors on liability to our three outcomes of interest: type 2 diabetes, coronary artery disease, and peripheral artery disease, using univariate Mendelian randomization. Common risk factors for liability to these outcomes included glycaemic traits, such as glucose (type 2 diabetes: $\mathrm{OR}=3.34,95 \% \mathrm{Cl}=2.41$ to 4.63 ; coronary artery disease, $\mathrm{OR}=1.25,95 \%$ $\mathrm{Cl}=1.11$ to 1.41 ; peripheral artery disease: $\mathrm{OR}=1.26,95 \% \mathrm{Cl}=1.10$ to 1.44 ) and anthropometric traits, such as body fat percentage (type 2 diabetes: $O R=2.78,95 \% \mathrm{Cl}=2.32$ to 3.32 ; coronary artery disease: $O R$ $=1.52,95 \% \mathrm{Cl}=1.33$ to 1.73 ; peripheral artery disease: $\mathrm{OR}=1.92,95 \% \mathrm{Cl}=1.68$ to 2.19 ). We also identified specific risk factors for each outcome. For instance, there were five risk factors with evidence to support an effect on liability to type 2 diabetes (whole body fat-free mass, whole body water mass, peak expiratory flow, lymphocyte count, IGF-1) but not liability to coronary or peripheral artery disease; as well as twelve and eight risk factors with specific effects on liability to coronary and peripheral artery disease respectively. These findings support continued control of the modifiable risk factors studied, independent of the diabetes control, to reduce the risk of these outcomes. 
medRxiv preprint doi: https://doi.org/10.1101/2021.08.05.21261658; this version posted August 7, 2021. The copyright holder for this preprint (which was not certified by peer review) is the author/funder, who has granted medRxiv a license to display the preprint in

It is made available under a CC-BY 4.0 International license.

Using two-step Mendelian randomization for mediation analysis, this study found that the effects of most of the eligible risk factors were likely to be independent of the effects of liability to type 2 diabetes. There are several reasons why a mediating effect may not have been identified in this analysis. Firstly, there could be no true mediating effect, so our findings reflect reality. Secondly, we may lack power to detect a mediating effect as the power requirements for multivariable Mendelian randomization are greater than univariate approaches and the number of risk factors considered in this study comes with a high multiple testing burden. Alternatively, the phenotypic complexity of liability to type 2 diabetes may be obscuring effects if, for example, a risk factor acts on a certain component of liability to type 2 diabetes that does not have a causal effect on liability to atherosclerotic cardiovascular disease. Partial mediation was observed for two risk factors: fasting insulin, which is difficult to separate from the clinical definition of type 2 diabetes, and hip circumference, though this particular risk factor was only an exception for the outcome liability to coronary artery disease. Several of the risk factors tested, including body mass index and waisthip-ratio, were identified as both causes and consequences of liability to type 2 diabetes and so were not studied using two-step Mendelian randomization for mediation, even if the magnitude of the effects heavily favoured a direction. Despite this, the strong causal effects observed for these risk factors on liability to coronary and peripheral artery disease, without consideration of liability to type 2 diabetes, indicate that they remain important risk factors for reducing the risk of atherosclerotic cardiovascular disease outcomes.

Four risk factors included in this study may be considered as part of the clinical definition of type 2 diabetes: fasting glucose, fasting insulin, glucose, and glycated haemoglobin (HbA1c). Except for fasting insulin, which was found to be a cause but not a consequence of liability to type 2 diabetes, these risk factors were deemed to have bidirectional relationships with liability to type 2 diabetes when interpreted using the arbitrary 5\% FDR threshold selected for this study. Given the interrelated nature of these glycaemic risk factors with liability to type 2 diabetes, this is perhaps unsurprising and highlights the difficultly in disentangling these effects. Nonetheless, these risk factors were important to include in our analysis given our aim of systematically assessing the effects of risk factors on liability to atherosclerotic cardiovascular disease risk.

Our study has some limitations. Mendelian randomization requires several assumptions to hold for valid estimates to be obtained. $(8,9)$ Except for relevance, these assumptions cannot be tested. However, where possible, we have performed sensitivity analyses and falsification tests. A further concern is the assumption of no interaction between risk factors and liability to type 2 diabetes that is necessary for the 
medRxiv preprint doi: https://doi.org/10.1101/2021.08.05.21261658; this version posted August 7, 2021. The copyright holder for this preprint (which was not certified by peer review) is the author/funder, who has granted medRxiv a license to display the preprint in

It is made available under a CC-BY 4.0 International license.

two-step Mendelian randomization for mediation. We cannot readily test this assumption using summary data, so the impact of any violation is difficult to quantify. For this reason, we were conservative in our approach to the analysis and did not perform two-step Mendelian randomization for mediation on any risk factors that had a bidirectional relationship with liability to type 2 diabetes at the 5\% FDR threshold. This should help to minimize the possibility of model misspecification. Our study may also be biased due to the non-collapsibility of odd ratios, which can impact estimates as a result of summary statistics from logistic regression being used for binary mediators (such as liability to type 2 diabetes) and outcomes (such as liability to coronary and peripheral artery disease). (11) We assessed this possibility by repeating our analyses with summary statistics from a novel GWAS that used a linear model for liability to type 2 diabetes and found little difference in the Mendelian randomization estimates we obtained (Supplementary Text 2; Supplementary Figure 10). This indicates that non-collapsibility of odds ratio is unlikely to have impacted our results. In addition, our study may be affected by horizontal pleiotropy. We used MR-Egger estimators to investigate whether our results were sensitive to assumptions about the structure of pleiotropy and found some evidence that a small number of risk factors may have horizontally pleiotropic effects. Finally, our study was restricted to individuals of European or mixed ancestry due to the broad range of GWAS required for the analysis. Consequently, the generalizability of the findings from this study is limited to comparable European or mixed ancestry populations.

In conclusion, we have used a Mendelian randomization framework to separate the effects of continuous risk factors from liability to type 2 diabetes and aid our understanding of their relationships with liability to coronary and peripheral artery disease. Our analysis suggests that some key risk factors - including diastolic blood pressure and hip circumference - act independently of liability to type 2 diabetes. Therefore, control of the modifiable risk factors included in this study is likely to reduce atherosclerotic cardiovascular disease, regardless of patient liability to type 2 diabetes.

\section{DATA AVAILABILITY STATEMENT}

All data used in this study are publicly available. We accessed genome-wide association study summary statistics for the risk factors from the IEU OpenGWAS database: https://gwas.mrcieu.ac.uk/; for liability to type 2 diabetes from the DIAMANTE consortium: https://www.diagram-consortium.org/; for liability to coronary artery disease from the CARDIoGRAM consortium: http://www.cardiogramplusc4d.org/; and for liability to peripheral artery disease from dbGAP: https://www.ncbi.nlm.nih.gov/gap/. Approved dbGAP access to phs001672.v6.p1 was provided to B.F.V. (dbGAP project ID: 27398). 
medRxiv preprint doi: https://doi.org/10.1101/2021.08.05.21261658; this version posted August 7, 2021. The copyright holder for this preprint (which was not certified by peer review) is the author/funder, who has granted medRxiv a license to display the preprint in It is made available under a CC-BY 4.0 International license.

\section{FUNDING STATEMENT}

VMW, ARC, NMD, GDS and TRG are members of the Medical Research Council Integrative Epidemiology Unit, which is supported by the Medical Research Council and the University of Bristol [MC_UU_00011/1, MC_UU_00011/4 and MC_UU_00011/6]. ARC is also supported by the University of Bristol British Heart Foundation Accelerator Award (AA/18/7/34219). NMD is also supported by a Norwegian Research Council [grant number 295989]. BFV is supported by the NIH/NIDDK (DK126194 and DK101478). M.S.U. is supported by NIDDK K23DK114551.

\section{CONFLICTS OF INTEREST STATEMENT}

TRG receives funding from Biogen for research unrelated to this manuscript. The authors of this manuscript have no other conflicts of interest to declare.

\section{ETHICS APPROVAL STATEMENT}

This research using UK Biobank was completed under Application Number 15825, which has been subject to ethics approval.

\section{CONTRIBUTION STATEMENT}

VMW, BV, TRG, and SMD contributed to the design of the work. VMW performed the data analysis and drafted the article. All authors contributed to the data interpretation, critical revision of the article, and final approval for publication.

\section{ACKNOWLEDGEMENTS}

Quality Control filtering of the UK Biobank data was conducted by R. Mitchell, G. Hemani, T. Dudding, Corbin, S. Harrison, L. Paternoster as described in the published protocol (doi:

10.5523/bris.1ovaau5sxunp2cv8rcy88688v). The MRC IEU UK Biobank GWAS pipeline was developed by B. Elsworth, R. Mitchell, C. Raistrick, L. Paternoster, G. Hemani, T. Gaunt (doi: 10.5523/bris.pnoat8cxo0u52p6ynfaekeigi).

The authors thank Million Veteran Program (MVP) staff, researchers, and volunteers, who have contributed to MVP, and especially participants who previously served their country in the military and 
medRxiv preprint doi: https://doi.org/10.1101/2021.08.05.21261658; this version posted August 7, 2021. The copyright holder for this preprint (which was not certified by peer review) is the author/funder, who has granted medRxiv a license to display the preprint in It is made available under a CC-BY 4.0 International license.

now generously agreed to enroll in the study. (See https://www.research.va.gov/mvp/ for more details). The citation for MVP is Gaziano, J.M. et al. Million Veteran Program: A mega-biobank to study genetic influences on health and disease. J Clin Epidemiol 70, 214-23 (2016). This research is based on data from the Million Veteran Program, Office of Research and Development, Veterans Health Administration, and was supported by the Veterans Administration (VA) Cooperative Studies Program (CSP) award \#G002. 
medRxiv preprint doi: https://doi.org/10.1101/2021.08.05.21261658; this version posted August 7, 2021. The copyright holder for this preprint (which was not certified by peer review) is the author/funder, who has granted medRxiv a license to display the preprint in It is made available under a CC-BY 4.0 International license.

\section{REFERENCES}

1. Bellou V, Belbasis L, Tzoulaki I, Evangelou E. Risk factors for type 2 diabetes mellitus: An exposurewide umbrella review of meta-analyses. PLOS ONE. 2018 Mar 20;13(3):e0194127.

2. Malakar AK, Choudhury D, Halder B, Paul P, Uddin A, Chakraborty S. A review on coronary artery disease, its risk factors, and therapeutics. J Cell Physiol. 2019;234(10):16812-23.

3. Song P, Rudan D, Zhu Y, Fowkes FJI, Rahimi K, Fowkes FGR, et al. Global, regional, and national prevalence and risk factors for peripheral artery disease in 2015: an updated systematic review and analysis. Lancet Glob Health. 2019 Aug 1;7(8):e1020-30.

4. Ahmad OS, Morris JA, Mujammami M, Forgetta V, Leong A, Li R, et al. A Mendelian randomization study of the effect of type-2 diabetes on coronary heart disease. Nat Commun. 2015 May 28;6:ncomms8060.

5. Criqui MH, Aboyans V. Epidemiology of Peripheral Artery Disease. Circ Res. 2015 Apr 24;116(9):150926.

6. Arnett DK, Blumenthal RS, Albert MA, Buroker AB, Goldberger ZD, Hahn EJ, et al. 2019 ACC/AHA Guideline on the Primary Prevention of Cardiovascular Disease: A Report of the American College of Cardiology/American Heart Association Task Force on Clinical Practice Guidelines. Circulation. 2019 Sep 10;140(11):e596-646.

7. Association AD. 3. Prevention or Delay of Type 2 Diabetes: Standards of Medical Care in Diabetes2021. Diabetes Care. 2021 Jan 1;44(Supplement 1):S34-9.

8. Davey Smith G, Ebrahim S. 'Mendelian randomization': can genetic epidemiology contribute to understanding environmental determinants of disease? Int J Epidemiol. 2003 Jan 2;32(1):1-22.

9. Davey Smith G, Hemani G. Mendelian randomization: genetic anchors for causal inference in epidemiological studies. Hum Mol Genet. 2014 Sep 15;23(R1):R89-98.

10. Relton CL, Davey Smith G. Two-step epigenetic Mendelian randomization: a strategy for establishing the causal role of epigenetic processes in pathways to disease. Int J Epidemiol. 2012 Feb;41(1):16176.

11. Carter AR, Sanderson E, Hammerton G, Richmond RC, Davey Smith G, Heron J, et al. Mendelian randomisation for mediation analysis: current methods and challenges for implementation. Eur J Epidemiol. 2021 May 1;36(5):465-78.

12. Burgess S, Davies NM, Thompson SG. Bias due to participant overlap in two-sample Mendelian randomization. Genet Epidemiol. 2016 Nov;40(7):597-608.

13. Ference BA, Yoo W, Alesh I, Mahajan N, Mirowska KK, Mewada A, et al. Effect of Long-Term Exposure to Lower Low-Density Lipoprotein Cholesterol Beginning Early in Life on the Risk of Coronary Heart DiseaseA Mendelian Randomization Analysis. J Am Coll Cardiol. 2012 Dec 25;60(25):2631-9.

14. Nelson CP, Hamby SE, Saleheen D, Hopewell JC, Zeng L, Assimes TL, et al. Genetically Determined Height and Coronary Artery Disease. N Engl J Med. 2015 Apr 23;372(17):1608-18. 
medRxiv preprint doi: https://doi.org/10.1101/2021.08.05.21261658; this version posted August 7, 2021. The copyright holder for this preprint (which was not certified by peer review) is the author/funder, who has granted medRxiv a license to display the preprint in perpetuity.

It is made available under a CC-BY 4.0 International license.

15. Corbin L, Richmond RC, Wade KH, Burgess S, Bowden J, Davey Smith G, et al. Body mass index as a modifiable risk factor for type 2 diabetes: Refining and understanding causal estimates using Mendelian randomisation. Diabetes. 2016 Jul 7; db160418.

16. Larsson SC, Bäck M, Rees JMB, Mason AM, Burgess S. Body mass index and body composition in relation to 14 cardiovascular conditions in UK Biobank: a Mendelian randomization study. Eur Heart J. 2020 Jan 7;41(2):221-6.

17. Huang $Y, X u M$, Xie L, Wang $T$, Huang $X, L v X$, et al. Obesity and peripheral arterial disease: $A$ Mendelian Randomization analysis. Atherosclerosis. 2016 Apr;247:218-24.

18. Gill D, Zuber V, Dawson J, Pearson-Stuttard J, Carter AR, Sanderson E, et al. Risk factors mediating the effect of body-mass index and waist-to-hip ratio on cardiovascular outcomes: Mendelian randomization analysis. $2020 \mathrm{Jul} 16$ [cited $2020 \mathrm{Jul}$ 29]; Available from: http://medrxiv.org/lookup/doi/10.1101/2020.07.15.20154096

19. Elsworth B, Lyon M, Alexander T, Liu Y, Matthews P, Hallett J, et al. The MRC IEU OpenGWAS data infrastructure. 2020 Aug 10 [cited 2020 Nov 5]; Available from: http://biorxiv.org/lookup/doi/10.1101/2020.08.10.244293

20. Sudlow C, Gallacher J, Allen N, Beral V, Burton P, Danesh J, et al. UK Biobank: An Open Access Resource for Identifying the Causes of a Wide Range of Complex Diseases of Middle and Old Age. PLOS Med. 2015 Mar 31;12(3):e1001779.

21. Mahajan A, Taliun D, Thurner M, Robertson NR, Torres JM, Rayner NW, et al. Fine-mapping type 2 diabetes loci to single-variant resolution using high-density imputation and islet-specific epigenome maps. Nat Genet. 2018 Nov;50(11):1505-13.

22. Nikpay M, Goel A, Won H-H, Hall LM, Willenborg C, Kanoni S, et al. A comprehensive 1,000 Genomesbased genome-wide association meta-analysis of coronary artery disease. Nat Genet. 2015 Oct;47(10):1121-30.

23. Klarin D, Lynch J, Aragam K, Chaffin M, Assimes TL, Huang J, et al. Genome-wide association study of peripheral artery disease in the Million Veteran Program. Nat Med. 2019;25(8):1274-9.

24. Gaziano JM, Concato J, Brophy M, Fiore L, Pyarajan S, Breeling J, et al. Million Veteran Program: A mega-biobank to study genetic influences on health and disease. J Clin Epidemiol. 2016 Feb;70:21423.

25. Bowden J, Davey Smith G, Burgess S. Mendelian randomization with invalid instruments: effect estimation and bias detection through Egger regression. Int J Epidemiol. 2015 Apr;44(2):512-25.

26. Spiller W, Davies NM, Palmer TM. Software application profile: mrrobust-a tool for performing twosample summary Mendelian randomization analyses. Int J Epidemiol. 2019 Jun 1;48(3):684-90.

27. Hemani G, Zheng J, Elsworth B, Wade KH, Haberland V, Baird D, et al. The MR-Base platform supports systematic causal inference across the human phenome. eLife. 2018 May 30; 7:e34408.

28. Benjamini Y, Hochberg Y. Controlling the False Discovery Rate: A Practical and Powerful Approach to Multiple Testing. J R Stat Soc Ser B Methodol. 1995;57(1):289-300. 
medRxiv preprint doi: https://doi.org/10.1101/2021.08.05.21261658; this version posted August 7, 2021. The copyright holder for this preprint (which was not certified by peer review) is the author/funder, who has granted medRxiv a license to display the preprint in

It is made available under a CC-BY 4.0 International license.

29. Sanderson E, Davey Smith G, Windmeijer F, Bowden J. An examination of multivariable Mendelian randomization in the single-sample and two-sample summary data settings. Int J Epidemiol. 2019 Jun $1 ; 48(3): 713-27$.

30. Details and considerations of the UK Biobank GWAS [Internet]. Neale lab. [cited 2019 May 1]. Available from: http://www.nealelab.is/blog/2017/9/11/details-and-considerations-of-the-ukbiobank-gwas

31. Dastani Z, Hivert M-F, Timpson N, Perry JRB, Yuan X, Scott RA, et al. Novel loci for adiponectin levels and their influence on type 2 diabetes and metabolic traits: a multi-ethnic meta-analysis of 45,891 individuals. PLoS Genet. 2012;8(3):e1002607.

32. Liu M, Jiang Y, Wedow R, Li Y, Brazel DM, Chen F, et al. Association studies of up to 1.2 million individuals yield new insights into the genetic etiology of tobacco and alcohol use. Nat Genet. 2019 Feb;51(2):237-44.

33. Lu Y, Day FR, Gustafsson S, Buchkovich ML, Na J, Bataille V, et al. New loci for body fat percentage reveal link between adiposity and cardiometabolic disease risk. Nat Commun. 2016 Feb 1;7:10495.

34. Yengo L, Sidorenko J, Kemper KE, Zheng Z, Wood AR, Weedon MN, et al. Meta-analysis of genomewide association studies for height and body mass index in $~ 700000$ individuals of European ancestry. Hum Mol Genet. 2018 Oct 15;27(20):3641-9.

35. Scott RA, Lagou V, Welch RP, Wheeler E, Montasser ME, Luan J, et al. Large-scale association analyses identify new loci influencing glycemic traits and provide insight into the underlying biological pathways. Nat Genet. 2012 Sep;44(9):991-1005.

36. den Hoed M, Eijgelsheim M, Esko T, Brundel BJJM, Peal DS, Evans DM, et al. Identification of heart rate-associated loci and their effects on cardiac conduction and rhythm disorders. Nat Genet. 2013 Jun;45(6):621-31.

37. Okbay A, Baselmans BML, Neve J-ED, Turley P, Nivard MG, Fontana MA, et al. Genetic variants associated with subjective well-being, depressive symptoms, and neuroticism identified through genome-wide analyses. Nat Genet. 2016 Jun;48(6):624-33.

38. Willer CJ, Schmidt EM, Sengupta S, Peloso GM, Gustafsson S, Kanoni S, et al. Discovery and refinement of loci associated with lipid levels. Nat Genet. 2013 Nov;45(11):1274-83.

39. Zanetti D, Bergman H, Burgess S, Assimes TL, Bhalla V, Ingelsson E. Urinary Albumin, Sodium, and Potassium and Cardiovascular Outcomes in the UK Biobank: Observational and Mendelian Randomization Analyses. Hypertens Dallas Tex 1979. 2020 Mar;75(3):714-22.

40. Shungin D, Winkler TW, Croteau-Chonka DC, Ferreira T, Locke AE, Mägi R, et al. New genetic loci link adipose and insulin biology to body fat distribution. Nature. 2015 Feb 12;518(7538):187-96. 
medRxiv preprint doi: https://doi.org/10.1101/2021.08.05.21261658; this version posted August 7, 2021. The copyright holder for this preprint (which was not certified by peer review) is the author/funder, who has granted medRxiv a license to display the preprint in It is made available under a CC-BY 4.0 International license.

Figure 1: Illustration of the two-stage study design (panel A) and the two-step Mendelian randomization for mediation models used for stage 2 (panels B and C)

(A)

(B)

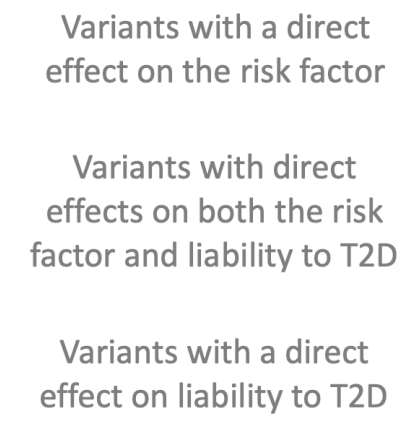

(C)

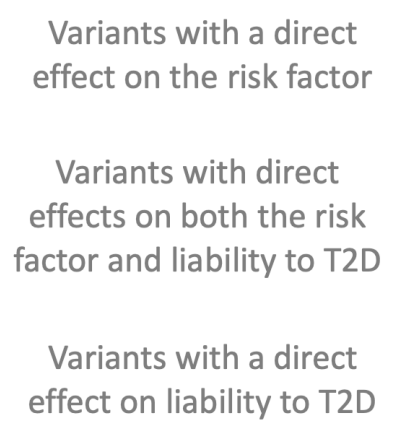

Stage 1

UVMR evidence for risk factor $>$ T2D

supportive

supportive

limited

limited

supportive

supportive

limited

limited
UVMR evidence for T2D > risk factor

supportive

limited

supportive

limited

supportive

limited

supportive

limited
Stage 2

UVMR evidence for

risk factor > ASCVD

supportive

supportive

supportive

supportive

limited

limited

limited

limited
Two-step MR

for mediation

none

(B)

(C)

none

none

none

none

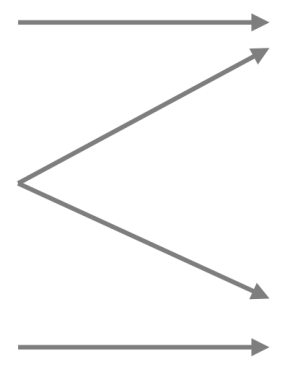

\section{Risk factor}

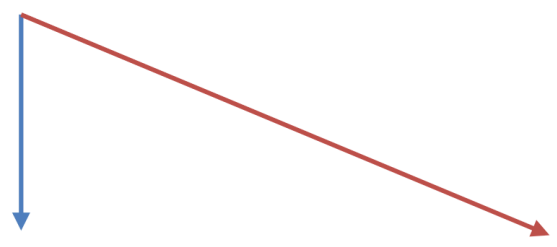

Liability to

ASCVD

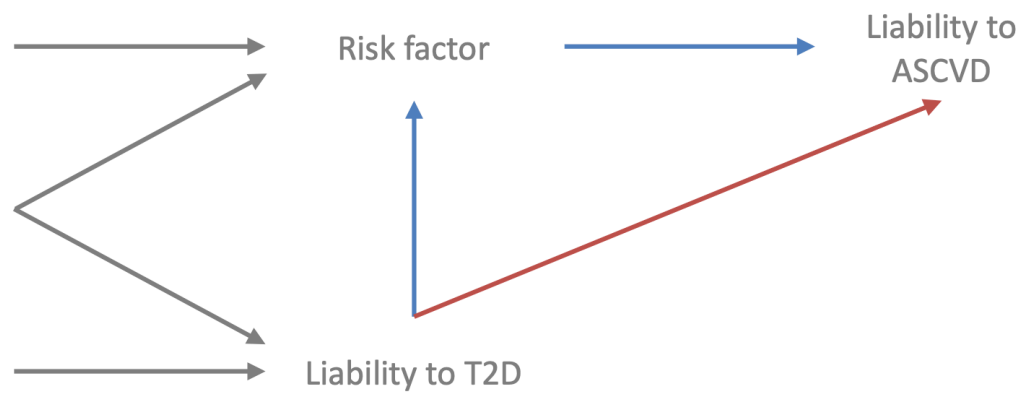

Panel A summarizes how evidence from univariate Mendelian randomization (UVMR) analyses of the risk factor, liability to type 2 diabetes (T2D), and liability to atherosclerotic cardiovascular diseases (ASCVD) is assessed in stage 1. Here, estimates that met the arbitrary false discovery rate threshold of 5\% were deemed to have 'supportive' evidence, while all other estimates were deemed to have 'limited' evidence. Stage 1 then informs the analysis models used in stage 2 for the two-step Mendelian randomization (MR) for mediation. These models are described in panels $B$ and $C$, where the red arrows represent the direct (i.e. independent of the mediator) effect and the blue arrows represent the indirect (i.e. via the mediator) effect. 
medRxiv preprint doi: https://doi.org/10.1101/2021.08.05.21261658; this version posted August 7, 2021. The copyright holder for this preprint (which was not certified by peer review) is the author/funder, who has granted medRxiv a license to display the preprint in It is made available under a CC-BY 4.0 International license.

Figure 2: Two-step Mendelian randomization for mediation estimates for the total, indirect (mediated by liability to type 2 diabetes) and direct (independent of liability to type 2 diabetes) effects of the indicated risk factors on liability to coronary artery disease

Total, OR: $1.80,95 \% \mathrm{Cl}: 1.60$ to 2.02 Indirect, OR: $0.98,95 \% \mathrm{Cl}: 0.89$ to 1.08 Direct, OR: $1.55,95 \% \mathrm{Cl}: 1.40$ to 1.71

Total, OR: $1.20,95 \%$ Cl: 1.07 to 1.34 Indirect, OR: $1.02,95 \% \mathrm{Cl}: 0.92$ to 1.13 Direct, OR: $1.15,95 \% \mathrm{Cl}: 1.02$ to 1.31

Total, OR: $1.79,95 \%$ Cl: 1.54 to 2.08 Indirect, OR: $1.03,95 \% \mathrm{Cl}: 0.91$ to 1.17 Direct, OR: $1.63,95 \% \mathrm{Cl}: 1.41$ to 1.87

Total, OR: $2.26,95 \%$ Cl: 1.47 to 3.50 Indirect, OR: $1.58,95 \% \mathrm{Cl}: 0.71$ to 3.53 Direct, OR: $1.53,95 \% \mathrm{Cl}: 1.05$ to 2.24

Total, OR: $1.14,95 \%$ Cl: 1.03 to 1.26 Indirect, OR: $1.07,95 \% \mathrm{Cl}: 0.91$ to 1.26 Direct, OR: $1.06,95 \% \mathrm{Cl}: 0.96$ to 1.18

Total, OR: $0.81,95 \%$ Cl: 0.77 to 0.86 Indirect, OR: $0.99,95 \% \mathrm{Cl}: 0.92$ to 1.06 Direct, OR: $0.78,95 \% \mathrm{Cl}: 0.71$ to 0.85 Total, OR: $1.52,95 \%$ Cl: 1.37 to 1.69 Indirect, OR: $0.98,95 \% \mathrm{Cl}: 0.88$ to 1.09 Direct, OR: $1.52,95 \% \mathrm{Cl}: 1.39$ to 1.67

Total, OR: $1.27,95 \%$ Cl: 1.13 to 1.43 Indirect, OR: $1.11,95 \% \mathrm{Cl}: 0.94$ to 1.32 Direct, OR: $1.25,95 \%$ Cl: 1.10 to 1.42 0.5
Apoliprotein B

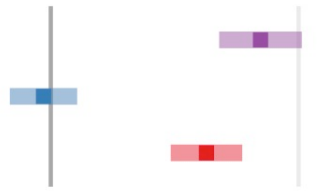

Aspartate aminotransferase

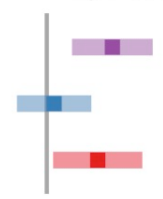

Diastolic blood pressure

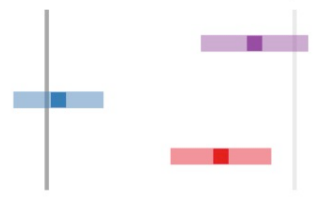

Fasting insulin

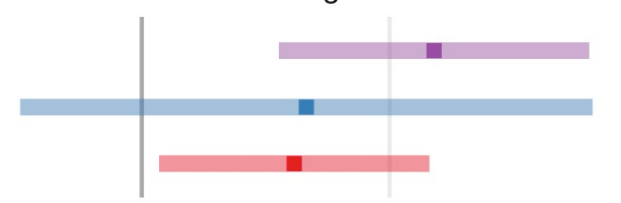

Hip circumference

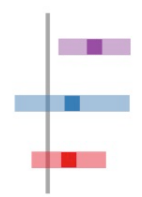

Standing height

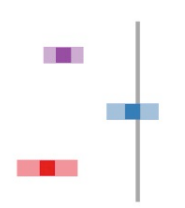

Total cholesterol

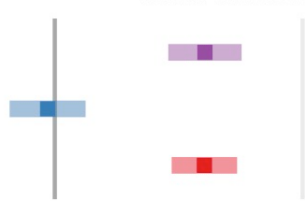

Trunk fat percentage

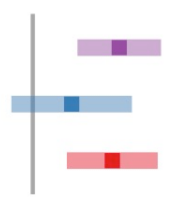

1.0 2.0 4.0

Odds ratio and $95 \%$ confidence interval for the effect of the risk factor on liability to coronary artery disease, mediated by liability to type 2 diabetes 
medRxiv preprint doi: https://doi.org/10.1101/2021.08.05.21261658; this version posted August 7, 2021. The copyright holder for this preprint (which was not certified by peer review) is the author/funder, who has granted medRxiv a license to display the preprint in It is made available under a CC-BY 4.0 International license.

Figure 3: Two-step Mendelian randomization for mediation estimates for the total, indirect (mediated by the indicated risk factor) and direct (independent of the indicated risk factor) effects of liability to type 2 diabetes on liability to coronary artery disease

Total, OR: $1.17,95 \% \mathrm{Cl}: 1.12$ to 1.21 Indirect, OR: $1.00,95 \% \mathrm{Cl}: 0.92$ to 1.09 Direct, OR: $1.17,95 \% \mathrm{Cl}: 1.13$ to 1.21

Total, OR: $1.17,95 \% \mathrm{Cl}: 1.12$ to 1.21 Indirect, OR: $1.00,95 \% \mathrm{Cl}: 0.92$ to 1.10 Direct, OR: $1.16,95 \% \mathrm{Cl}: 1.12$ to 1.20

Total, OR: $1.17,95 \% \mathrm{Cl}: 1.12$ to 1.21 Indirect, OR: $1.01,95 \% \mathrm{Cl}: 0.82$ to 1.23 Direct, OR: $1.22,95 \% \mathrm{Cl}: 1.16$ to 1.27

Total, OR: $1.17,95 \% \mathrm{Cl}: 1.12$ to 1.21 Indirect, OR: $1.01,95 \% \mathrm{Cl}: 0.89$ to 1.14 Direct, OR: $1.16,95 \% \mathrm{Cl}: 1.12$ to 1.20
Mean corpuscular haemoglobin

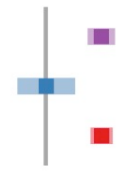

Mean sphered cell volume

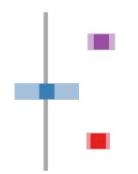

Testosterone

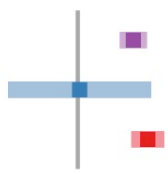

Urate

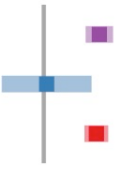

1.0

2.0 4.0

Odds ratio and $95 \%$ confidence interval for the effect of liability to type 2 diabetes on liability to coronary artery disease, mediated by the risk factor 
medRxiv preprint doi: https://doi.org/10.1101/2021.08.05.21261658; this version posted August 7, 2021. The copyright holder for this preprint (which was not certified by peer review) is the author/funder, who has granted medRxiv a license to display the preprint in It is made available under a CC-BY 4.0 International license.

Figure 4: Two-step Mendelian randomization for mediation estimates for the total, indirect (mediated by liability to type 2 diabetes) and direct (independent of liability to type 2 diabetes) effects of the indicated risk factors on liability to peripheral artery disease

Total, OR: $1.17,95 \% \mathrm{Cl}: 1.08$ to 1.26 Indirect, OR: $0.97,95 \% \mathrm{Cl}: 0.89$ to 1.07 Direct, OR: $1.34,95 \% \mathrm{Cl}: 1.22$ to 1.48

Total, OR: $1.27,95 \%$ Cl: 1.11 to 1.44 Indirect, OR: $1.05,95 \% \mathrm{Cl}: 0.93$ to 1.18 Direct, OR: $1.20,95 \% \mathrm{Cl}: 1.06$ to 1.35

Total, OR: $2.51,95 \%$ Cl: 1.42 to 4.46 Indirect, OR: $1.91,95 \% \mathrm{Cl}: 0.86$ to 4.25 Direct, OR: $1.32,95 \% \mathrm{Cl}: 0.92$ to 1.89

Total, OR: $1.31,95 \%$ Cl: 1.19 to 1.45 Indirect, OR: $1.10,95 \% \mathrm{Cl}: 0.93$ to 1.29 Direct, OR: $1.26,95 \% \mathrm{Cl}: 1.13$ to 1.40

Total, OR: $1.15,95 \%$ Cl: 1.05 to 1.26 Indirect, OR: $0.97,95 \% \mathrm{Cl}: 0.88$ to 1.08 Direct, OR: $1.19,95 \% \mathrm{Cl}: 1.11$ to 1.28

Total, OR: $1.68,95 \% \mathrm{Cl}: 1.49$ to 1.89 Indirect, OR: $1.15,95 \% \mathrm{Cl}: 0.98$ to 1.37 Direct, OR: $1.40,95 \%$ Cl: 1.23 to 1.59
Apoliprotein B

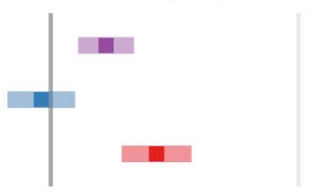

Diastolic blood pressure

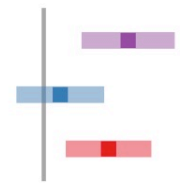

Fasting insulin

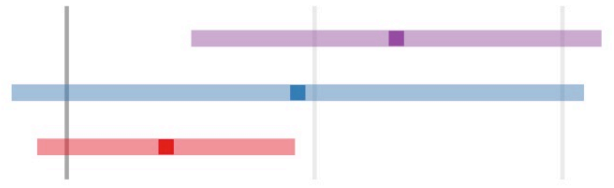

Hip circumference

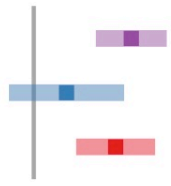

Total cholesterol

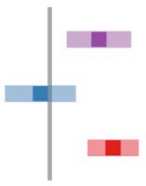

Trunk fat percentage

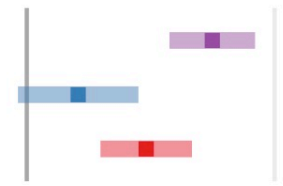

1.0

2.0 4.0

Odds ratio and $95 \%$ confidence interval for the effect of the risk factor on liability to peripheral artery disease, mediated by liability to type 2 diabetes 
medRxiv preprint doi: https://doi.org/10.1101/2021.08.05.21261658; this version posted August 7, 2021. The copyright holder for this preprint (which was not certified by peer review) is the author/funder, who has granted medRxiv a license to display the preprint in It is made available under a CC-BY 4.0 International license.

Figure 5: Two-step Mendelian randomization for mediation estimates for the total, indirect (mediated by the indicated risk factor) and direct (independent of the indicated risk factor effects of liability to type 2 diabetes on liability to peripheral artery disease

Total, OR: $1.24,95 \% \mathrm{Cl}: 1.20$ to 1.29 Indirect, OR: $1.02,95 \% \mathrm{Cl}: 0.86$ to 1.20 Direct, OR: $1.23,95 \% \mathrm{Cl}: 1.16$ to 1.29

Total, OR: $1.24,95 \% \mathrm{Cl}: 1.20$ to 1.29 Indirect, OR: $1.01,95 \% \mathrm{Cl}: 0.80$ to 1.27 Direct, OR: $1.24,95 \% \mathrm{Cl}: 1.18$ to 1.29

Total, OR: $1.24,95 \% \mathrm{Cl}: 1.20$ to 1.29 Indirect, OR: $1.01,95 \% \mathrm{Cl}: 0.89$ to 1.15 Direct, OR: $1.22,95 \% \mathrm{Cl}: 1.18$ to 1.26
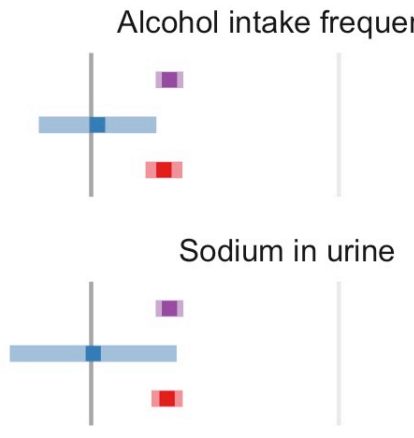

Urate

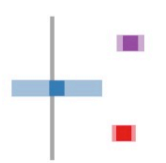

1.0

Odds ratio and $95 \%$ confidence interval for the effect of liability to type 2 diabetes on liability to peripheral artery disease, mediated by the risk factor 